\title{
Application of SCS-CN Model in Runoff Estimation
}

\author{
Dake Wang ${ }^{1}$, Liangqiong Qin $^{2}$, Bao Chang ${ }^{1}$, Mingxing Wang ${ }^{1}$, Weihua Zhang ${ }^{1 *}$ \\ ${ }^{1}$ College of Resources \& Environment, Southwest University, Chongqing, China \\ ${ }^{2}$ Zhongxian Water Resource Bureau, Zhongxian, Chongqing, China
}

Abstract. Runoff calculation is an important part of regional runoff forecast and water resources evaluation model. The Soil Conservation Service (SCS) curve number (CN) model developed by the U.S. Department of Agriculture National Resources Conversion Service (NRCS) is the most popular and widely applied model for direct runoff estimation. This article will introduce the basic principles of SCS model, review and summary the application, development and improvement of the model, points out the shortcomings of the existing model. Finally, prospects for the future development of this model are conducted.

\section{Introduction}

\subsection{The features of SCS-CN model}

The SCS-CN method is one of the most popular methods for computing the volume of direct surface runoff for a given rainfall event. On one hand, SCS model is an empirical model and it just needs a single parameter-Curve Number which lumps together the hydrological impacts of land use. So the model structure is simplified, the model calibration can also be easily realized and the functions surface characteristics make on the runoff can be reflected well. On the other hand, due to its low input data requirements, it can also be applied to hydrological forecasts of the ungauged watersheds and city.

\subsection{Fundamental principle}

The establishment of SCS-CN method is an empirical equation predicting runoff from rainfall using a parameter $\mathrm{CN}$ (or S) based on soil, vegetation, land use, and soil moisture prior to a rainfall event. Its establishment is based on one water balance equation and two basic assumptions ${ }^{[1]}$. The two basic assumptions are initial abstraction and equal proportions, respectively.

Water balance equation:

$$
P=I_{a}+F+Q
$$

Where $\mathrm{P}(\mathrm{mm})$ is rainfall; $\mathrm{I}_{\mathrm{a}}(\mathrm{mm})$ is initial abstraction; $\mathrm{F}$ $(\mathrm{mm})$ is cumulative infiltration, it does not include $\mathrm{I}_{\mathrm{a}}$; Q $(\mathrm{mm})$ is direct runoff.

The equal proportions assumption can be described as the ratio of runoff and rainfall equals to the ratio of cumulative infiltration and the potential maximum retention. And the equation can be expressed as follows:

$$
\frac{Q}{P-I_{a}}=\frac{F}{S}
$$

Where $\mathrm{S}$ is the potential maximum retention $(\mathrm{mm})$ after runoff begins.

The initial abstraction assumption which shows the relation between initial abstraction and the potential maximum retention $\mathrm{S}$ can be expressed as follows:

$$
I_{a}=\lambda S
$$

Where $\lambda$ is regional parameter, it depends on the geographic and climatic factors.

According to the Eq. (1) and Eq. (2), the SCS model could be expressed in its general form as follows:

$$
Q=\frac{\left(P-I_{a}\right)}{P-I_{a}+S}
$$

The SCS-CN model originally estimated the initial abstraction as a constant $20 \%$ of the maximum potential retention(S), based on available rainfall-runoff measurements in 1954. When $\lambda$ is set to 0.2 , the Eq. (4) becomes the well-known original SCS-CN model as below:

$$
Q=\frac{(P-0.2 S)^{2}}{P+0.8 S}
$$

for $\mathrm{P}>0.2 \mathrm{~S}$, else $\mathrm{Q}=0$

According to the Eq. (5), the relationship graph between them when $\mathrm{CN}$ is in different values can be shown as figure. 1

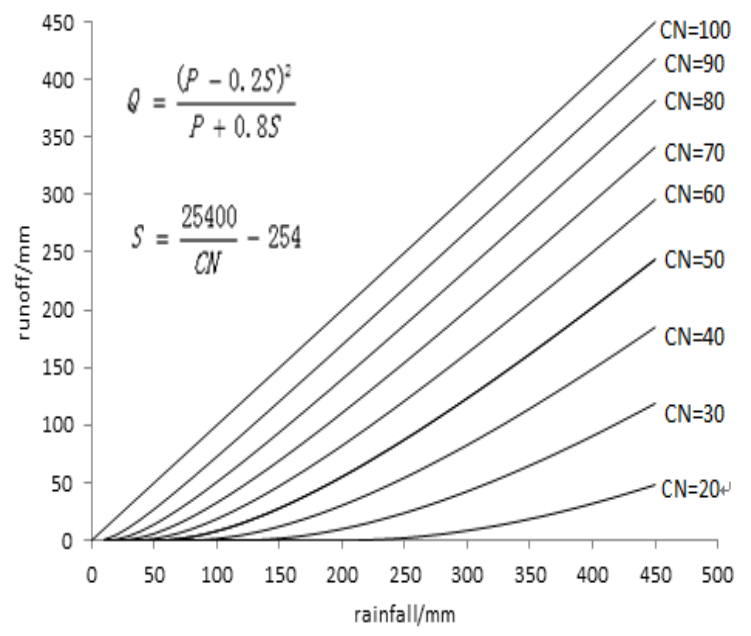

Figure.1 Relationship between runoff and rainfall

In order to calculate $\mathrm{S}$, the $\mathrm{CN}$ is cited. The empirical relationship between $\mathrm{S}$ and $\mathrm{CN}$ is

$$
S=\frac{25400}{C N}-254
$$




\section{Application of SCS-CN model}

\subsection{CN values determination}

\subsubsection{Soil hydrological conditions}

The hydrologic soil conditions are divided into four groups: $\mathrm{A}, \mathrm{B}, \mathrm{C}$ and $\mathrm{D}$ according to runoff and storage capacity by the soil scientists. The runoff features of each soil type can be described as follows ${ }^{[1]}$. A: strong permeability, low runoff potential, high infiltration rate and hydraulic conductivity when fully saturated. B: relatively strong infiltration capacity or an impermeable layer in a certain depth of soil profile, high penetration rate when fully saturated. C: moderate permeability, sandy soil with an impermeable layer in a certain part of soil profile, secondary infiltration rate when wetted. D: weak permeability, and high runoff potential. The specific division is in the following table. 1

Table.1 Hydrologic soil group

\begin{tabular}{ccc}
\hline Soil type & $\begin{array}{c}\text { The minimum } \\
\text { infiltration } \\
\text { rate }(\mathrm{mm} / \mathrm{h})\end{array}$ & Soil texture \\
\hline A & $>7.26$ & $\begin{array}{c}\text { Sand, loamy sand } \\
\text { and sandy loam. } \\
\text { Powder sand and } \\
\text { loam. }\end{array}$ \\
C & $3.81-7.26$ & $\begin{array}{c}\text { Sandy clay loam. } \\
\text { Clay loam, silty. } \\
\text { clay loam, sandy } \\
\text { clay, silty clay and } \\
\text { clay. }\end{array}$ \\
\hline
\end{tabular}

When the Hydrologic soil groups are determined, the CNII values can be got through searching The National Engineering Handbook integrated with the vegetation, land use and hydrologic conditions.

\subsubsection{Antecedent soil moisture}

The soil moisture before rainfall will significantly affects surface runoff capacity and $\mathrm{CN}$ values because it can check and balance the infiltration rate and quantity. Considering the effects, the SCS divided the antecedent soil moisture content (AMC) represented by Antecedent Precipitation Index the 5-day antecedent rainfall amount into three levels: AMCI (dry), AMCII (normal) and AMCIII (wet). The formula of API is:

$$
A P I=\sum_{i=1}^{5} P_{i}
$$

Where $P_{i}$ is the rainfall amount.

The Specific division basis is on the following table2.
Table.2 Types of antecedent soil condition in SCS-CN method

\begin{tabular}{ccc} 
AMC Levels & \multicolumn{2}{c}{ 5-day antecedent rainfall amount $(\mathrm{mm})$} \\
\cline { 2 - 3 } 1 & Growing season & Dormant season \\
2 & $<35.6$ & $<12.7$ \\
3 & $35.6 \sim 53.3$ & $12.7 \sim 27.9$ \\
& $>53.3$ & $>27.9$ \\
\hline
\end{tabular}

\subsubsection{The determination of $\mathrm{CN}$ values}

The $\mathrm{CN}$ values in normal wetness conditions can be determined through NEH integrated with other conditions, such as land use and hydrologic conditions. The values of other two AMC levels can be got according to the conversion formulas ${ }^{[2]}$ shown as below:

$$
\begin{gathered}
C N(I)=\frac{4.2 C N(I I)}{10-0.058 C N(I I)} \\
C N(I I I)=\frac{23 C N(I I)}{10-0.12 C N(I I)}
\end{gathered}
$$

When the $\mathrm{CN}$ values are determined, the runoff estimation can be made combined with given rainfall account.

\section{Shortcomings of this model}

\subsection{Drawbacks of AMC levels}

Various studies have revealed that runoff estimations using the original SCS-CN tables with AMC-II do not satisfactorily represent real flood measurements or include sufficient periods of flood records for the design of $\mathrm{CN}$ calibration. Many watersheds are either ungauged or lack sufficient flood data to estimate reliable $\mathrm{CN}$ values from observed data. In addition, the classifications of AMC levels are ambiguous. It will lead to the sudden increase or decrease for $\mathrm{S}$ values and the accuracy of this model is decreased. There is a high subjectivity during the using process. This classification method of the AMC can threaten the model stability.

\subsection{Without considering the rainfall conditions}

The rainfall intensity, duration and spatial and temporal distribution will have certain influences on the initial abstraction and $\mathrm{CN}$ values. While, the SCS-CN model don't take them into consideration. So the effects caused by these factors on estimation accuracy and model efficiency are inevitable in its extensive promotion and long term application.

\subsection{The land condition}

The SCS-CN model is originally designed for hydrological forecasting in the light of small watershed. The model doesn't refer to the watershed of large size. So it application is limited to a certain extent.

Though there are a lot of studies about the SCS model, only a few attempts have been made for incorporation of 
slope factor in the existing SCS-CN method. The main factors affecting increase in surface runoff due to steeper slope can also be the reduction of initial abstraction, decrease in infiltration, and reduction of the recession time of overland flow. Slope is the important factors that can influence runoff. And simulation results of the model will not be ideal without considering the slope ${ }^{[3]}$.

\section{Improvement of SCS model}

Since the SCS-CN model has been widely used, it should also be improved due to the huge difference in climate conditions, soil types, rainfall characteristics and so on among countries of the world. And a lot of studies have been made on the improvement of SCS model. These improvement methods focus on the re-calibration of $\mathrm{CN}$ and directly determination of initial abstraction or potential maximum retention.

\subsection{Re-calculation of CN}

If the SCS model was directly applied to other countries, the big errors will be made. One of the improvement methods is to re-calculate the $\mathrm{CN}$ values.
The $\mathrm{CN}$ values can be calculated According to Eq. (5) and Eq. (6) from the mathematical point:

$$
\begin{gathered}
C N=\frac{B-\sqrt{B^{2}-4 A C}}{2 A} \\
A=(5 P+254)^{2}-Q(25 P-5080) \\
B=50800(5 P+254)+508000 Q \\
C=25400^{2}
\end{gathered}
$$

According to the observed rainfall-runoff data, the $\mathrm{CN}$ values of different land use can be determined.

\subsection{The effects on $\mathrm{CN}$ values made by slopes}

More parameters are taken into consideration with the development the SCS model. So the effects on the runoff must be emphasized. And many studies have been made

\begin{tabular}{|c|c|c|c|}
\hline No. & Researcher & Research content & Research findings \\
\hline 1 & Dodds W K (1997) & $\begin{array}{l}\text { Distribution of runoff and rivers related to } \\
\text { vegetative characteristics, latitude ,and } \\
\text { slope }\end{array}$ & Slope increases, the rainfall increases ${ }^{[4]}$ \\
\hline 3 & Chaplot (2003) & Agricultural loessial hillslope & $\begin{array}{l}\text { The correlation between surface runoff and slope is } \\
\text { higher than that of rainfall intensity }{ }^{[6]}\end{array}$ \\
\hline 4 & Philip J R (1991) & Hill slope infiltration:planar slopes & $\begin{array}{l}\text { Slope infiltration capacity decreases by } 15 \% \\
\text { compared to the level }^{[7]}\end{array}$ \\
\hline 5 & EI-Hassanin (1993) & Watersheds of Burundi & $\begin{array}{l}\text { The slope gradient increased from } 8 \% \text { to } 30 \% \text {, and } \\
\text { the runoff increased by } 160 \%\end{array}$ \\
\hline 6 & Evett S R (1985) & $\begin{array}{l}\text { Length and slope effects on runoff from } \\
\text { Sodium dispersed,compacted earth micro } \\
\text { catchments }\end{array}$ & $\begin{array}{l}\text { The slope increases, the withdrawal period } \\
\qquad \text { decreases }^{[9]}\end{array}$ \\
\hline 7 & Huang C H (1995) & $\begin{array}{l}\text { Empirical analysis of slope and runoff for } \\
\text { sediment delivery from interrill areas }\end{array}$ & $\begin{array}{l}\text { The average runoff depth will increases with slope } \\
\qquad \text { increasing }\end{array}$ \\
\hline
\end{tabular}
to research the influence made by slope, just as shown in table.3.

Table.3 Studies about the effects of slope on runoff 
These studies all indicate that it is reasonable to take the slope into consideration. And then, considering the effects of slopes on the runoff, the $\mathrm{CN}$ values from the $\mathrm{NEH}$ can be adjusted as follows ${ }^{[11]}$

$$
C N(I I)^{\prime}=C N(I I) \frac{322.79+15.63 \alpha}{\alpha+323.52}
$$

Where $\alpha\left(\mathrm{mm}^{-1}\right)$ is the land slope.

And the other corresponding $\mathrm{CN}$ values of this slope can be calculated according to the Eq. (8) and Eq. (9).

\subsection{Revising initial abstraction ratio}

$\mathrm{CN}$ values can be got from National Engineering Handbook. The values of $\lambda$ can be set to a range according to the rainfall conditions. For example, if the rainfall-runoff happened in rainy season, there is a lot of vegetation and the slope steep, the runoff account is large, and then the initial abstraction ratio values can be assumed more than 0.2 . The values can be $0.21,0.22$, 0.23 etc. Putting each value into the formula (4).The calculated runoff values can be got.

\section{4 evaluation criteria}

In order to evaluate the effectiveness of the each model with different $\mathrm{m}$ values, the Nash model effective coefficient $\left(\mathrm{E}_{\mathrm{f}}\right)$ and relative error $(\mathrm{RE})$ can be chose as evaluation criteria.

$$
\begin{gathered}
E_{f}=1-\frac{\sum\left(Q_{o b s i}-Q_{c a l i}\right)^{2}}{\sum\left(Q_{o b s i}-Q_{o b s}\right)^{2}} \\
R E=\left(\frac{Q_{c a l i}}{Q_{o b s i}}-1\right) \times 100 \%
\end{gathered}
$$

Where $Q_{o b s i}$ is the observed runoff value, $Q_{\text {cali }}$ is the computed runoff value, $Q_{o b s}$ is the average observed runoff value.

The $E_{f}$ ranges from $-\infty \sim 1$. The closer $E_{f}$ value is to1, the better its effectiveness is. So the most optimal initial abstraction ratio can be determined. Many researchers have made lot of studies in this content to make this model more suitable for the runoff estimation of the study region.

\section{Future outlook}

With the development of modern science and technology, more and more scientists apply the GIS and remote sensing technology to the SCS model. So, the soil characteristics and land use types can be obtained by the remote sensing image. And the $\mathrm{CN}$ values of different soil types are determined by regression analysis. Now, the related investigation is continuing. The combination of the model and these technologies will be more mature and universal. In addition, model improvement studies are also conducted by scientists of the world. The application of SCS-CN model certainly will be more universal, the application results will be more accurate.

\section{Acknowledgements}

This research was supported by "Water Resources Protection and Development of Qinba Mountainous Area in Chongqing-the Sub-topic under Major Consulting Project of Chinese Academy of Engineering", the support was gratefully acknowledged.

\section{References}

[1] Chen Z W. Runoff estimation in hillslope cropland of purple soil based on SCS-CN model. Trans. Chin. Soc. Agric.Eng. 30, 72-81(2014).

[2] Gao Y. Application of SCS model to estimate the Volume of Rainfall Runoff in Sloping Field of Purple Soil. Chin. Agric. Sci. Bull. 22, 396400(2006).

[3] Huang M B, Jacques, et al. A modification to the soil conservation service curve number method for steep slopes in the loess plateau of China. Hydro. Process. 19, 1-11(2005).

[4] Dodds W K. Distribution of runoff and rivers related to vegetative characteristics, latitude, and slope: a global perspective. J. N. Am. Benthol. Soc. 16, 162168(1997).

[5] Wang X T, Wang Y K, Fu B, etc. Experimental study on runoff characteristics of slope land in Sichuan Basin. J. Soil Water Conserv. 20, 9-12(2006).

[6] Chaplot V M, Bissonnais Y L. Runoff features for interrill erosion at different rainfall intensities, slope lengths, and gradients in an agricultural loessial hillslope. Soil Sci. Soc. Am. J. 67, 844-851 (2003).

[7] Philip J R. Hill slope infiltration: planar slopes. Water Resour. Res. 27, 109-117(1991).

[8] Ei-hassanin A S, Labib T M, Gaber E I. Effect of vegetation cover and land slope on runoff and soil losses from the watersheds of Burundi. Agr. Ecosyst. Environ. 43, 301-308(1993).

[9] Evett S R, Dutt G R. Length and slope effects on runoff from sodium dispersed, compacted earth micro catchments. Soil Sci. Soc. Am. J. 49, 734738(1985).

[10] Huang C H. Empirical analysis of slope and runoff for sediment delivery from interrill areas. Soil Sci. Soc. Am. J. 59, 982-990(1995).

[11] Zhang Y X. The calibration of Runoff Curve Number Model (SCS-CN) parameters in Loess Hilly Region. Agric. Res. Arid Areas. 26, 124-128(2008).

[12] Fang X D. Application of Runoff Curve Number Method (SCS method) in rainfall runoff calculation-Taking the example of the runoff test plot in Shixia, Miyun. J. Cap. Nor. Uni. 28, 89-92(2007).

[13] Menberu, M.,Haghighi, A., Ronkanen, A., Kværner, J., and Kløve, B. Runoff Curve Numbers for Peat DominatedWatersheds.J.Hydro.Eng.20,1038-1049 (2014). 
[14] Peng D Z. Application of improved SCS model in runoff simulation of river basin. J.Water Resour.\& Water Eng. 17, 20-24(2006). 